\title{
Modelling of Piezoelectric Actuator (PEA) for Advanced Process Control in Chemical Mechanical Polishing (CMP)
}

\author{
Jing-Hang Liu, William J. O'Connor, Eamonn Ahearne, and Gerald Byrne
}

\begin{abstract}
Lead zirconate titanate (PZT) stacks are commonly used for submicron resolution actuation, fast response times and high sensitivity. They are usually modeled as expansion generators without external load. This paper proposes an electromechanical model for a commercially available micro-piezoelectric actuator (PEA) which comprises pre-stressed PZT stacks and external amplifier flexure frame for closed loop force control. The proposed model avoids the need to measure the piezoelectric charge which is usually required in conventional electromechanical models. The mechanical part of the PEA was modeled as a linear, lumped, double mass-spring-damper system and the related parameters were experimentally identified. The PEA system was characterised under load-free and load-applied conditions, and the electromechanical coupling ratios which describe the energy transfer from the electrical domain (voltage) to the mechanical domain (endpoint displacement/force) were experimentally determined.
\end{abstract}

Index Terms-Electromechanical modeling, micro-piezoelectric actuator, parameter identification, force control.

\section{NOMENCLATURE}

$v_{i n}$ total input voltage of the PEA system, $\mathrm{V}$

$v_{e} \quad$ effective voltage of the PEA system, $\mathrm{V}$

$v_{z} \quad$ voltage on amplifier resistance, $\mathrm{V}$

$f_{\text {ext }}$ external applied force to the PEA, $\mathrm{N}$

$f_{p z t}$ exerted force by the PZT stacks, $\mathrm{N}$

$n_{e m}$ electromechanical coupling factor, $\mathrm{NV}^{-1}$

$t_{e m}$ electromechanical coupling factor, $\mathrm{mV}^{-1}$

$z \quad$ resistance of the PEA amplifier, $\Omega$

$c$ constant capacitance of the PEA,F

$k_{p z t} \quad$ stiffness of the PZT stacks, $\mathrm{Nm}^{-1}$

$k_{s} \quad$ stiffness of PEA preload springs, $\mathrm{Nm}^{-1}$

$m_{1}, m_{2}$ equivalent mass of the PEA, $\mathrm{kg}$

$k_{1}, k_{2}$ equivalent stiffness of the PEA, $\mathrm{Nm}^{-1}$

$b_{1}, b_{2}$ equivalent damper value of the PEA, $\mathrm{Nsm}^{-1}$

$x_{1} \quad$ endpoint displacement of the PEA, $\mathrm{m}$

$x_{2}$ modelling displacement of the PEA, $m$

$\delta$ total electric transformed displacement, $\mathrm{m}$

$h$ nonlinear hysteresis displacement, $\mathrm{m}$

$S$ strain tensor

$T$ stress tensor, $\mathrm{Nm}^{-2}$

Manuscript received June 15, 2012; revised October 18, 2012.

J. Liu, E. Ahearne, and G. Byrne are with the Advanced Manufacturing Science (AMS) Research Centre, School of Mechanical and Materials Engineering, University College Dublin, Ireland (e-mail: jinghang.liu@ucd.ie, eamonn.ahearne@ucd.ie, gerald.byrne@ucd.ie).

W. J. O'Connor is with the School of Mechanical and Materials Engineering, University College Dublin, Ireland (e-mail: william.oconnor@ucd.ie).

\author{
$E \quad$ electric field vector, $\mathrm{Vm}^{-1}$ \\ $X$ output displacement, $\mathrm{m}$ \\ $V$ exerted voltage to the PZT stacks, V \\ $\hat{s}_{33}$ elastic compliance, $\mathrm{m}^{2} \mathrm{~N}^{-1}$ \\ $d_{33}$ material constants, $\mathrm{mV}^{-1}$ or $\mathrm{CN}^{-1}$ \\ $A$ cross-section of the PZT cylinder, $\mathrm{mm}^{2}$ \\ $l \quad$ length of the PZT cylinder, $\mathrm{m}$ \\ $k$ stiffness of the PEA, $\mathrm{Nm}^{-1}$ \\ $\omega_{i} \quad$ the $i^{t h}$ resonance frequency in Bode plot $(i=1,2)$, \\ $\operatorname{rads}^{-1}$
}

\section{INTRODUCTION}

Chemical mechanical polishing (CMP) is described as "the process of smoothing and planarising synergistically aided by combined chemical and mechanical effects" [1] which is widely used for planarisation in semiconductor manufacturing. The Advanced Manufacturing Science (AMS) Research Centre at UCD is pioneering a new concept for advanced process control, called multifunctional intelligent tooling (MIT), with the potential to provide a major improvement in the interfacial pressure control between the silicon wafer and polishing pad [2]-[3]. In the proposed system, a long range micro-piezoelectric actuator is used as a force generator rather than its more common use in motion control. Models for relating voltage to displacement in PZT stacks can be divided into two major types: models based on or partly derived from PZT linear constitutive equations [4], and electromechanical models describing the electrical and mechanical energy transformations considering the nonlinear hysteresis between voltage and charge [5]-[9]. Constitutive equation based models treat the stacks as a linear component by ignoring the nonlinear behaviour of PZT, to which hysteresis is the most significant contributor. By contrast, electromechanical models adopt hysteresis operators to describe the nonlinear relationship between voltage and charge. Accordingly, charge measurement is essential since charge is the only index to indicate the accuracy of the hysteresis model. However, charge measurement is not recommended or not possible for some applications, for example where the disassembly for identification would have negative consequences for the whole system. This arises when the PZT stacks are pre-stressed and housed by the flexure amplifier mechanism, as in the PEA used in this project. In addition, the charge measurement is usually costly and has limited sensitivity.

\section{ElectromechanicAl Model OF THE PEA}

The actuator used here is a commercial product, 
"Flextensional Piezoelectric ActuatorTM" (Dynamic Structures and Materials (DSM) LLC, Franklin, USA) which is composed of PZT stacks and flexure-hinged displacement amplifier frame, as shown in Fig. 1 and Fig. 2. The PZT layers were stacked in parallel acting as the strain generator and the generated deformation will be magnified by the flexible mechanism so as to exert a relatively larger output displacement. The gain of amplification is determined by the geometric dimensions of links, and the direction of motion is changed from horizontal to vertical.

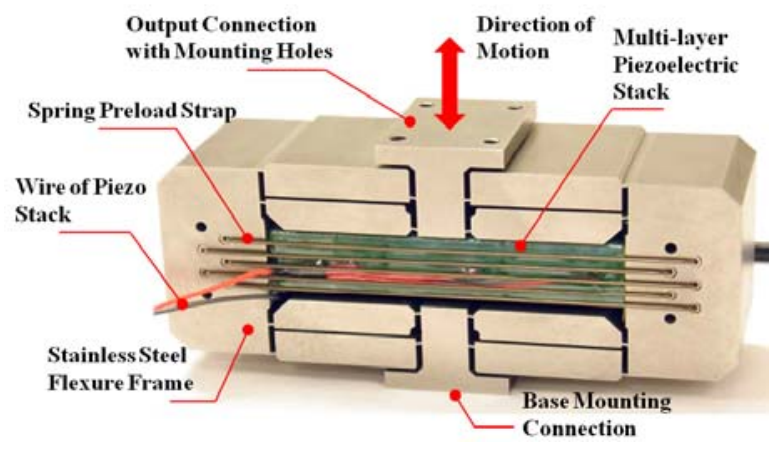

Fig. 1. The flextensional piezoelectric actuator ${ }^{\mathrm{TM}}$ fabricated by DSM

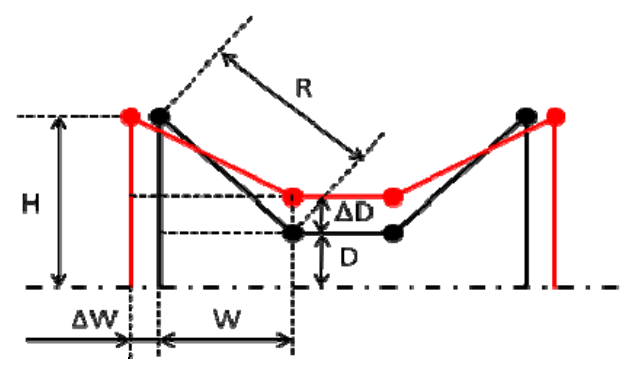

Fig. 2. Simplified structure of the flexure-hinged frame in PEA

The improved electromechanical mathematical model is represented in Fig. 3. This model moved the hysteresis operator from the electrical domain to the mechanical domain to avoid charge measurement. The hysteresis operator should be capable of providing resistance to the complex static or dynamic external loads. The PEA mechanical part was viewed as a linear, lumped double mass-spring-damper system governed by both piezoelectric equations and Newton's Law. The electric and mechanical domains are connected by the electromechanical coupling factors which can be experimentally determined.

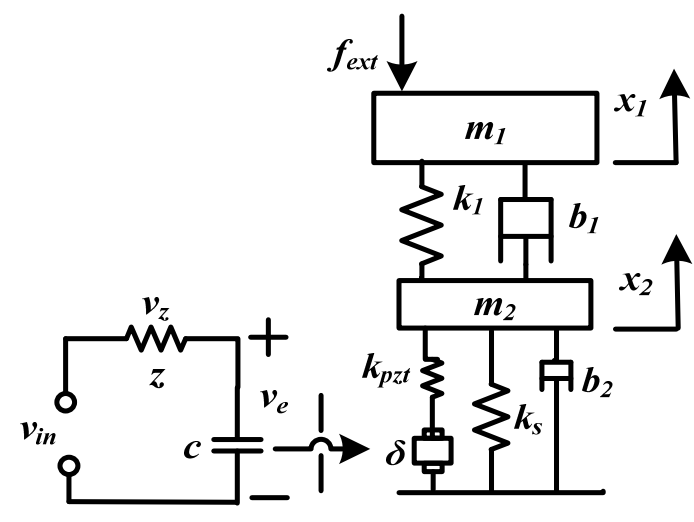

Fig. 3. Improved electromechanical model of the PEA

The mathematical description of the model can be expressed by (1) to (6).

$$
\begin{gathered}
v_{i n}=z c \dot{v}_{e}+v_{e} \\
f_{p z t}(t)=k_{p z t} \times \delta \\
\delta=t_{e m} v_{e}+h \\
k_{2}=k_{p z t}+k_{s} \\
{\left[\begin{array}{cc}
m_{1} & 0 \\
0 & m_{2}
\end{array}\right]\left[\begin{array}{ll}
\ddot{x}_{1}(t) \\
\ddot{x}_{2}(t)
\end{array}\right]+\left[\begin{array}{ll}
b_{1} & -b_{1} \\
-b_{1} & b_{1}+b_{2}
\end{array}\right]\left[\begin{array}{l}
\dot{x}_{1}(t) \\
\dot{x}_{2}(t)
\end{array}\right]} \\
+\left[\begin{array}{cc}
k_{1} & -k_{1} \\
-k_{1} & k_{1}+k_{2}
\end{array}\right]\left[\begin{array}{l}
x_{1}(t) \\
x_{2}(t)
\end{array}\right]=\left[\begin{array}{l}
f_{e x t}(t) \\
f_{p z t}(t)
\end{array}\right]
\end{gathered}
$$

where $\delta$ represents the total transformed expansion of the PZT material which is composed of linear displacement and nonlinear hysteresis displacement. The electromechanical coupling factor $t_{e m}$, stiffness of the PEA $k$, equivalent masses $m_{1}, m_{2}$, equivalent damper values $b_{1}, b_{2}$ and equivalent stiffnesse $k_{l}, k_{2}$ are the parameters that need to be identified.

\section{IDENTIFICATION OF THE SYSTEM}

The actuator was characterised under two different working conditions: load-free and load-exerted. In the load-free condition, one side of the PEA was fixed to a rigid support and the other side was free (under no load); in the load-exerted condition, the PEA was fixed in a closed structural loop in a Hounsfield universal materials testing machine (Tinius Olsen, Inc., Horsham, PA, USA) such that the preload force exerted on the PEA can be adjusted by the Hounsfield machine, as shown in Fig. 4. The force sensor is a piezoelectric force sensor with a measurement range of $\pm 5 \mathrm{KN}$ and resolution of $1 \mathrm{mVN}^{-1}$ (Kistler Instrument $\mathrm{GmbH}$, Ostfildern, Germany) while the displacement sensor is a non-contact capacitive displacement sensor (Micro-Epsilon, GmbH \& Co. KG, Ortenburg, Germany) with nanometre resolution. A National Instruments compact controller (model cRIO-9022, National Instruments (NI) Co., Austin, TX, USA) was used. The analog input and output modules combined with the NI controller are capable of simultaneous data acquisition and arbitrary signal generation.

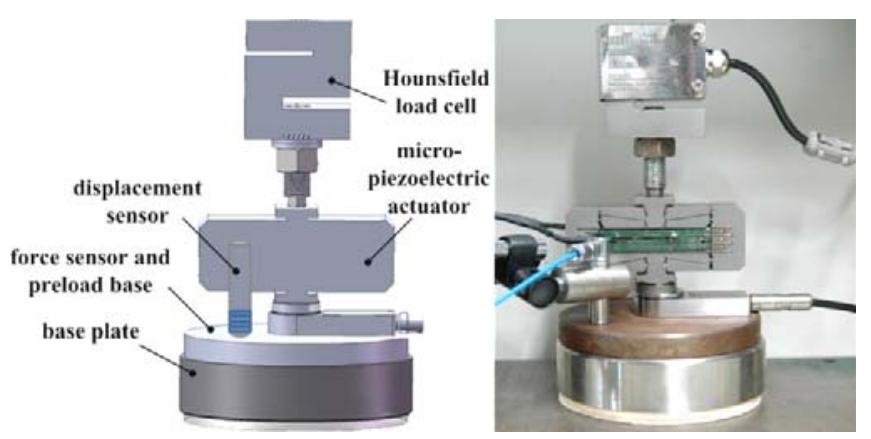

Fig. 4. The load-exerted experimental setup

The test programme described below was designed in NI 
LabVIEW $^{\mathrm{TM}}$ to accomplish the PEA characterisation and modelling parameters identification, as shown in Fig. 5. The programme involves generating control signals to the PEA and monitoring/recording the response. The responses of PEA were experimentally investigated based on different types of driving signals: sinusoidal or triangle waveforms with controllable parameters (amplitude, offset, phase, update rate, etc).

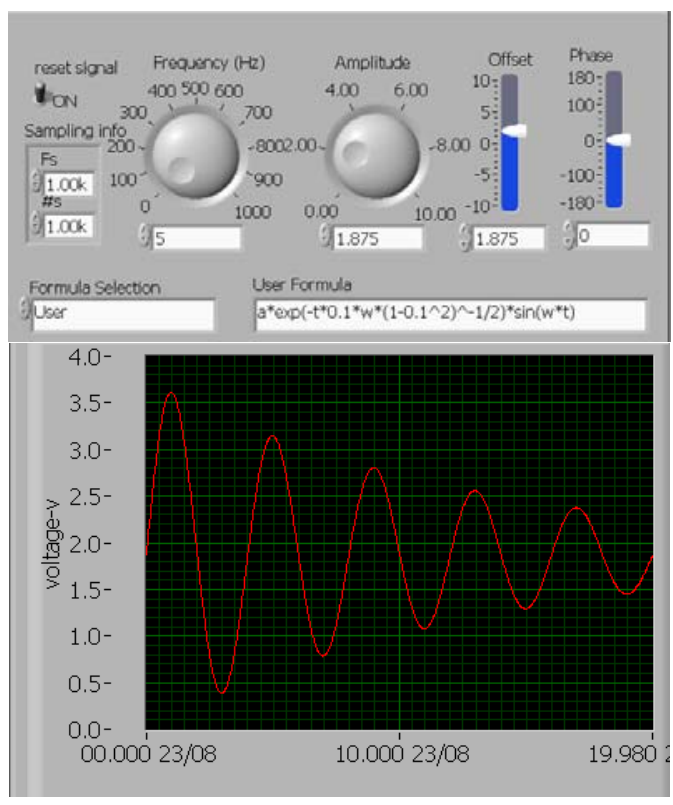

Fig. 5. The front panel of the programme in NI lab VIEW ${ }^{\mathrm{TM}}$

\section{A. Coupling Factors Identification}

Assuming the PZT component is a cylindrical disk of cross section $A$ and length $l$, the relationship between external force, input voltage and the output displacement can be derived by the PEA constitutive equation (7).

$$
\begin{gathered}
S=\hat{s}_{33} T+d_{33} E \\
f_{\text {ext }}=\left[\begin{array}{ll}
\frac{A}{l \hat{s}_{33}} & -\frac{A d_{33}}{l \hat{s}_{33}}
\end{array}\right]\left[\begin{array}{l}
X \\
V
\end{array}\right]=\left[\begin{array}{ll}
k & -k_{l}
\end{array}\right]\left[\begin{array}{l}
X \\
V
\end{array}\right] \\
=k\left[\begin{array}{ll}
1 & -d_{33}
\end{array}\right]\left[\begin{array}{l}
X \\
V
\end{array}\right]
\end{gathered}
$$

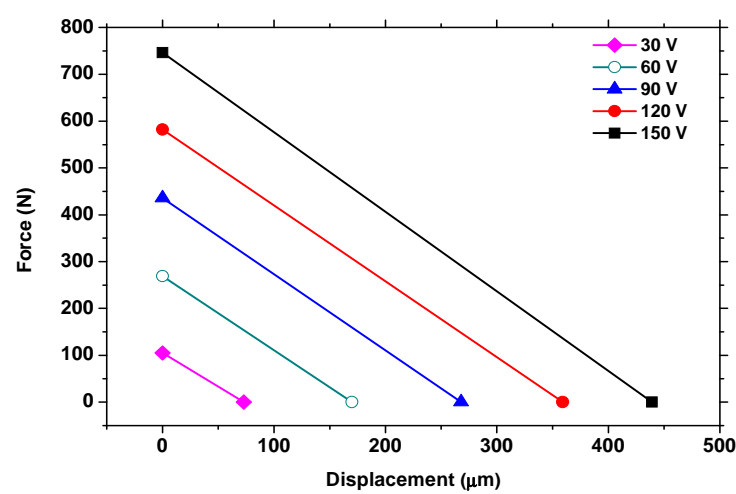

Fig. 6. The PEA characterisation under different voltages

Equation (8) indicates that the induced displacement is directly proportional to input voltage when the external load remains constant, and similarly, the external force is proportional to the voltage when the displacement remains constant. Five control voltages (30, 60, 90, 120 and 150V) were selected in the identification process, as shown in Fig. 6. The average identified value of coupling factors are listed in Table I. $N_{e m}$ and $T_{e m}$ slightly varied with voltage, as shown in Fig. 7. This is due to the inherent nonlinearity of coupling factors when the piezoelectric materials are subject to high control voltages [8]-[10].

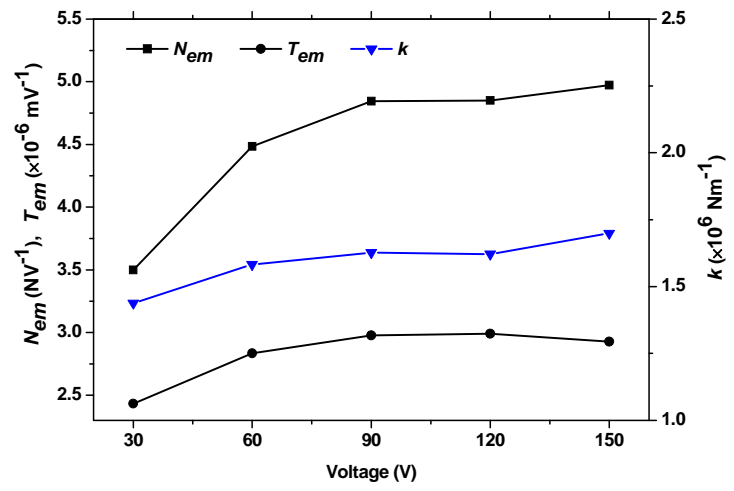

Fig. 7. The identified coupling factors

TABLE I: AVERAGE IDENTIFIED ELECTROMECHANICAL COUPLING FACTORS AND STIFFNESS OF THE PEA

\begin{tabular}{llll}
\hline \hline Parameters & Description & $\begin{array}{l}\text { Identifie } \\
\text { d value }\end{array}$ & Units \\
\hline$T_{e m}$ & $\begin{array}{l}\text { electromechanical coupling } \\
\text { from input voltage to endpoint } \\
\text { (amplified) displacement }\end{array}$ & 2.8 & $\times 10^{-6} \mathrm{mV}^{-1}$ \\
& $\begin{array}{l}\text { electromechanical coupling } \\
\text { from input voltage to endpoint } \\
N_{e m}\end{array}$ & 4.5 & $\mathrm{NV}^{-1}$ \\
$k$ & $\begin{array}{l}\text { force } \\
\text { stiffness of the PEA }\end{array}$ & 1.6 & $\times 10^{6} \mathrm{Nm}^{-1}$ \\
\hline \hline
\end{tabular}

\section{B. Dynamic Parameters Identification}

To identify the parameters $m_{1}, m_{2}, b_{1}, b_{2}$ and $k_{1}, k_{2}$, the dynamic property of the PEA was investigated under load-free condition. The magnitude of the measured Bode curve in Fig. 8 represents endpoint displacement divided by the external force exerted on the actuator as the input is swept over the frequency range of 0 to $500 \mathrm{~Hz}$. The amplitude of the input was $80 \mathrm{~V}$ and the sampling rate was up to $10^{5} \mathrm{~Hz}$.

The values of the first resonance frequency, $\omega_{l}$, and the frequency of the zero of the response, $\omega_{0}$, were experimentally determined from the measured Bode curve. The relationship between equivalent masses $m_{1}, m_{2}$ and equivalent stiffnesse $k_{1}, k_{2}$ were expressed as in (9), (10), under the assumption that the damper values $b_{1}, b_{2}$ and external force $f_{p z t}$ were temporarily assumed to be zero. With the values of $m_{1}, m_{2}, k_{l}$ and $k_{2}$ identified from (5) and (9), (10), the damper values $b_{1}, b_{2}$ were chosen to obtain a good match between model and measured frequency responses, as shown in Table II.

$$
\begin{aligned}
& \omega_{1,2}^{2}=\frac{k_{1} m_{2}+\left(k_{1}+k_{2}\right) m_{1}}{2 m_{1} m_{2}} \\
& \mp \sqrt{\frac{1}{4}\left(\frac{k_{1}}{m_{1}}-\frac{\left(k_{1}+k_{2}\right)}{m_{2}}\right)^{2}+\frac{\left(-k_{1}\right)^{2}}{m_{1} m_{2}}} \\
& \omega_{0}^{2}=\frac{k_{1}+k_{2}}{m_{2}}
\end{aligned}
$$


TABLE II: IDENTIFIED PARAMETERS OF THE PEA DyNAMIC MODEL

\begin{tabular}{llllll}
\hline \hline $\begin{array}{l}\text { Parame } \\
\text { ters }\end{array}$ & $\begin{array}{l}\text { Identified } \\
\text { value }\end{array}$ & Units & $\begin{array}{l}\text { Parame } \\
\text { ters }\end{array}$ & $\begin{array}{l}\text { Identified } \\
\text { value }\end{array}$ & Units \\
\hline$m_{1}$ & 0.25 & $\mathrm{~kg}$ & $m_{2}$ & 5.62 & $\mathrm{~kg}$ \\
$b_{1}$ & 55.0 & $\mathrm{Nsm}^{-1}$ & $b_{2}$ & 1.0 & $\mathrm{Nsm}^{-1}$ \\
$k_{1}$ & 1.62 & $\times 10^{6} \mathrm{Nm}^{-1}$ & $k_{2}$ & 40 & $\times 10^{6} \mathrm{Nm}^{-1}$ \\
\hline \hline
\end{tabular}

The simulated Bode plot based on the listed parameters is compared with the measured curve in Fig. 8. It shows good matching between the simulated and measured responses, especially in the useful frequency range below $10^{3} \mathrm{rads}^{-1}$. the proposed model therefore can represent the actuator dynamics with sufficient accuracy.

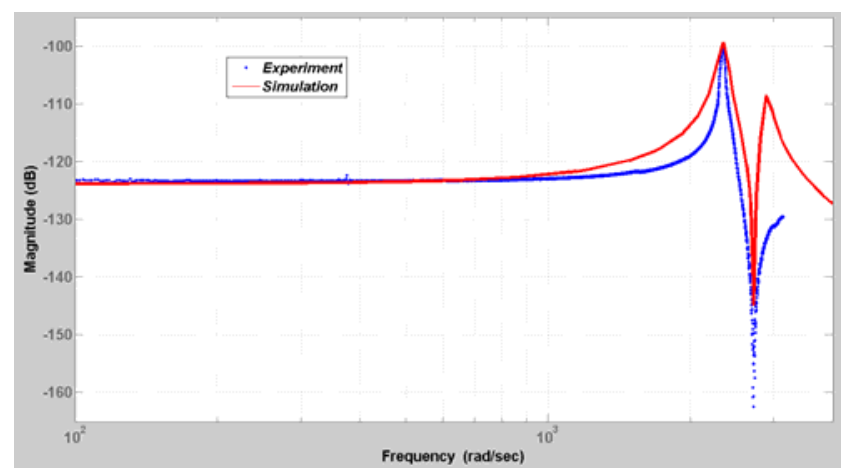

Fig. 8. Measured Bode curve (blue points) and the simulated Bode curve (red line)

\section{CONCLUSIONS}

An improved electromechanical model is presented for a commercially available PEA composed of pre-stressed PZT stacks and an external amplifier flexure mechanism. Characterisations were accomplished when the PEA was working under load-free and load-exerted conditions and the voltage-displacement electromechanical coupling coefficient and voltage-force electromechanical coupling coefficient were experimentally identified. The mechanical part of the PEA was modeled as a linear, lumped double MSD system governed by both piezoelectric constitutive equations and Newton's Law. The equivalent parameters were experimentally identified and verified.

\section{REFERENCES}

[1] J. M. Steigerwald, S. P. Murarka, and R. J. Gutmann, Chemical Mechanical Planarization of Microelectronic Materials, New York: John Wiley \& Sons, 1997.

[2] J. Liu, E. Ahearne, and G. Byrne, "Characterisation of the External Loading Conditions of an Advanced Process Control System Integrated with Piezoelectric Actuator (PEA) in Chemical Mechanical Polishing (CMP)," in Proc. 2011 28th International Manufacturing Conf., Dublin, pp. 1-8, 2011.

[3] J. Liu, E. Ahearne, and G. Byrne, "Characterisation of the Transfer Function of an Advanced Process Control System for Chemical Mechanical Polishing (CMP)," in Proc. 2011 11th International Conference of the European Society for Precision Engineering \& Nanotechnology, Como, vol. 1, pp. 311-314, 2011.

[4] S. B. Choi and Y. M. Han, Piezoelectric Actuators Control Applications of Smart Materials, New York: CRC Press Taylor \& Francis, 2010, ch. 4, pp. 71-72.

[5] M. Goldfarb and N. Celanovic, "Modeling piezoelectric stack actuators for control of micromanipulation," IEEE Control Systems, pp. 69-79, June 1997.

[6] H. J. M. T. S. Adriaens, W. L. D. Koning, and R. Banning, "Modeling piezoelectric actuators," IEEE/ASME Transactions on Mechatronics, vol. 5, no. 4, pp. 331-341, 2000.
[7] H. M. S. Georgiou and R. B. Mrad, "Electromechanical Modeling of Piezoceramic Actuators for Dynamic Loading Applications," Journal of Dynamic Systems, Measurement, and Control, vol. 128, no. 3, pp. 558-567, 2006.

[8] M. Quant, H. Elizalde, A. Flores, R. Ramírez, P. Orta, and G. Song, "A comprehensive model for piezoceramic actuators: modelling, validation and application," Smart Materials and Structures, vol. 18, pp. 1-16, Dec. 2009.

[9] L. Juhász, J. Maas, and B. Borovac, "Parameter identification and hysteresis compensation of embedded piezoelectric stack actuators," Mechatronics, vol. 21, no. 1, pp. 329-338, Feb. 2011.

[10] H. L. H. Richter, E. A. Misawa, and D. A. Luccaa, "Modeling nonlinear behavior in a piezoelectric actuator," Precision Engineering, vol. 25, no. 2, pp. 128-137, Apr. 2001.

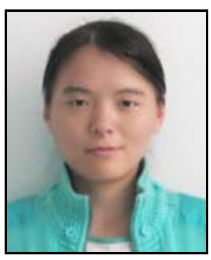

Jinghang Liu received the B.Sc. degree in the School of Mechatronics Engineering at Harbin Institute of Technology (HIT), China, in 2005. She then joined the "Nanopositioning and Micromanipulation Laboratory" in the Robotics Institute of HIT, where she received the M.Sc. degree in Mechatronics Engineering in 2008. Currently she is a Ph.D. student in the Advanced Manufacturing Science (AMS) Research Centre, UCD, National University of Ireland, Dublin, Ireland, in the School of Mechanical and Materials Engineering. Her research interests include piezoelectric actuator numerical modeling methods, integration of sensors and position control in Chemical Mechanical Planarisation (CMP), a process used extensively in the semiconductor industry.

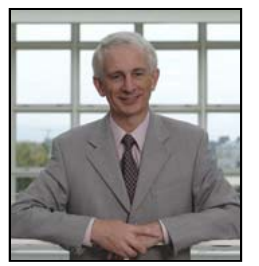

William J O'Connor obtained a doctorate from University College Dublin in 1976 on magnetic fields and forces for pole geometries with saturable materials. He is a Senior Lecturer in the School of Mechanical and Materials Engineering in UCD, National University of Ireland, Dublin, lecturing in Mechanics, Dynamics and Control. Dr O’Connor has published 30 papers in top international refereed journals, presented about 50 refereed papers at international conferences and co-authored a book on TLM applied to continuum mechanics. He has been external examiner to many PhD theses in Ireland, the UK and Spain. He has been voted "lecturer of the year" several times by his students. He currently has a research contract with ESA (European Space Agency) to apply wave-based control to large, flexible space structures.

Dr O'Connor's research interests include control and active vibration damping of elastic mechanical systems; numerical modelling methods, particularly TLM (Transmission Line Matrix); theoretical mechanics; analysis and design of acoustic devices; waves and wave-structure interaction; development of special-purpose acoustic and infrared sensors; and analysis and computation of non-linear magnetic fields and forces.

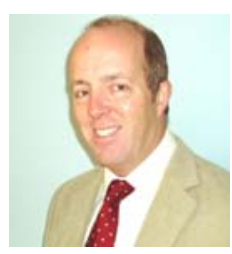

Eamonn Ahearne obtained a doctorate from University College Dublin in 2008. He is Centre Manager in the AMS Research Centre at UCD. Dr Ahearne has a unique mix of experience in both academia and industry, with over 18 years experience in senior engineering roles in the automotive sector. Dr Ahearne is an Associate Member of the International Academy for Production Engineering (CIRP) and a Corporate Member of the European Society for Precision Engineering and Nanotechnology (Euspen).

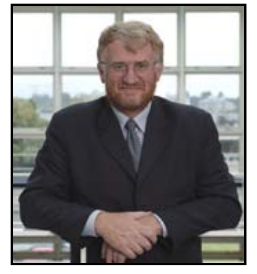

Gerald Byrne is the Director of the Advanced Manufacturing Science (AMS) Research Centre which is based in the School of Electrical, Electronic and Mechanical Engineering at University College Dublin. Professor Byrne is an Active Member of the Collége International pour l'Étude Scientifique des Techniques de Production Mécanique (C.I.R.P.) and a member of its Council. He is a former Chairman of the CIRP Editorial Board and is currently Chairman of the Scientific Technical Committee "Cutting" (STC"C"). He is the Dean of Engineering, Head of Department of Mech. Eng.UCD. Professor Byrne is a former President of the Institution of Engineers of Ireland and of the Irish Academy of Engineering. He is an International Fellow of the Royal Academy of Engineering, UK [FREng] and a life time Fellow of the Society of Manufacturing Engineers (USA). 